\title{
Strategi Peningkatan Daya Saing TV Kabel Lokal (Studi Kasus PT DKM)
}

\author{
Improvement Strategy of Local Cable TV Competitiveness (Case Study of PT DKM)
}

\author{
M. Kadafi Amru*1, Heny K. Daryanto ${ }^{1}$, dan Bunasor Sanim ${ }^{1}$
}

${ }^{1}$ Sekolah Bisnis, Institut Pertanian Bogor

Jl. Raya Pajajaran, Bogor 16151

\begin{abstract}
ABSTRAK
PT DKM adalah perusahaan yang bergerak di bidang TV Kabel yang berlokasi di Kota Payakumbuh. Hingga akhir 2016 jumlah pelanggan tercatat 3,037 pelanggan. Berdasarkan data internal PT DKM, jangkauan jaringan dan pelanggan TV kabel telah mencapai $40 \%$ dari luas wilayah pemukiman Kota Payakumbuh. Posisi PT DKM sebagai pemimpin pasar dalam industri TV berbayar di Kota Payakumbuh belum menunjukkan bahwa PT DKM sebagai perusahaan yang kuat yang dapat memenangkan persaingan dalam jangka panjang. Perencanaan strategik TV kabel lokal PT DKM perlu dianalisis agar dapat memenangkan persaingan pada industri TV berbayar di Kota Payakumbuh. Tujuan penelitian adalah (1) menganalisis kondisi persaingan PT DKM dalam industri TV berbayar di Kota Payakumbuh, (2) menganalisis faktor-faktor internal dan eksternal PT DKM, dan (3) merumuskan strategi alternatif yang dapat diimplementasikan untuk meningkatkan daya saing PT DKM. Penelitian ini menggunakan metode analisis Porter's Five Forces, matriks EFE (External Factor Evaluation),IFE (Internal Factor Evaluation), IE (Internal External) dan SWOT (Strength Weaknesses, Opportunities and Threats), dan ANP (Analytic Network Process) untuk menentukan strategi alternatif terbaik bagi peningkatan daya saing PT DKM. Hasil penelitian menunjukkan kondisi persaingan industri TV berbayar di Kota Payakumbuh berada pada tingkat kondusif. Faktor internal yang memiliki skor tertinggi berupa kekuatan adalah harga berlangganan sangat kompetitif dan kelemahan utama adalah terbatasnya jumlah channel favorit. Sementara faktor eksternal paling dominan berupa peluang, yaitu banyaknya penyedia content TV kabel; dan ancaman perusahaan, yaitu semakin bertambahnya kompetitor. Berdasarkan analisis ANP diperoleh strategi yang paling direkomendasikan untuk meningkatkan daya saing PT DKM adalah strategi meningkatkan kerja sama dengan content provider terbaik.
\end{abstract}

Kata kunci: daya saing, metode ANP, strategi, TV berbayar, TV kabel

ABSTRACT

PT DKM is a company engaged in the field of Cable TV located in Payakumbuh. By the end of 2016 there are 3,037 subscribers. Based on internal data of PT DKM, network coverage and cable TV subscribers has reached $40 \%$ of Payakumbuh's residential area. Position of PT DKM as a market leader in Pay TV industry in Payakumbuh has not shown that PT DKM as a strong company that can win the competition in the long run. Strategic planning of local cable TV PT DKM needs to be analyzed in order to win the competition in Pay TV industry in Payakumbuh. The purpose of this study is (1) analyze the condition of competition PT DKM in pay TV industry in Payakumbuh, (2) to analyze internal and external factors of PT DKM, and (3) to formulate alternative strategies that can be implemented to improve the competitiveness of PT DKM. This research uses Porter's Five Forces analysis method, EFE (External Factor Evaluation), IFE (Internal Factor Evaluation), IE (Internal External) and SWOT (Strength Weaknesses, Opportunities and Threats) matrix, and ANP (Analytical Network Process) to determine the best alternative strategy for increasing competitiveness of PT DKM. Result of the ANP analysis show that condition of pay TV industry competition in Payakumbuh is at a condusive level. Internal factors that have the highest score of strength are highly competitive subscription prices and the main drawback is the limited number of favorite channels. While the dominant external factors in the form of opportunities

\footnotetext{
*) Korespondensi:

Sekolah Bisnis IPB Jl. Raya Pajajaran, Bogor; email: mdafi_25@yahoo.com; Hp: 081288683038
} 
is the number of cable TV content providers; and corporate threats of increasing competitors. Based on analysis the most recommended strategy to improve the competitiveness of PT DKM is a strategy to increase cooperation with the best content provider.

Key words: ANP method, cable TV, competitiveness, pay TV

\section{PENDAHULUAN}

Saat ini perkembangan industri media semakin pesat apabila dibandingkan dengan kondisi beberapa tahun lalu. Hal tersebut disebabkan adanya keterbukaan informasi dengan teknologi yang semakin modern, sehingga menempatkan TV kabel sebagai alternatif pilihan konvergensi teknologi dan konvergensi media. TV merupakan salah satu media yang berperan penting dalam penyebaran informasi dan hiburan kepada masyarakat. Kebutuhan masyarakat akan informasi maupun hiburan semakin meningkat, tidak hanya dari golongan menengah ke atas, tetapi juga masyarakat menengah ke bawah. Secara langsung maupun tidak, TV dapat memengaruhi persepsi maupun perilaku seseorang. TV Kabel dapat dimanfaatkan masyarakat untuk mendapatkan informasi tentang apa saja termasuk informasi daerahnya, serta program lainnya sebagai opsi tayangan yang ditonton pemirsa. Menurut data Balitbang
Sumber Daya Manusia (SDM) Kemkominfo tahun 2015 bahwa akses rumah tangga terhadap siaran televisi secara nasional berdasarkan indikator Teknologi, Informasi dan Komunikasi (TIK) 86,7 persen atau setara 56,4 juta rumah tangga.

TV kabel dengan nama lain Cable TV Operator (CTO) mengalami pertumbuhan yang cukup pesat selama beberapa tahun terakhir (ICTA 2016). Menurut data Subdit Layanan Televisi Direktorat Penyiaran Direktorat Jenderal Penyelenggaraan Pos dan Informatika Kemkominfo hingga Agustus 2016 tercatat ada 369 perusahaan TV kabel yang telah memiliki Izin Penyelenggaraan Penyiaran (IPP). Data sebaran TV kabel lokal di seluruh Indonesia yang telah memiliki IPP dapat dilihat pada Gambar 1.

Menurut data ICTA (2015) terdapat lebih dari 1.000 CTO yang tersebar di seluruh wilayah Indonesia, salah satunya berada di Kabupaten Payakumbuh. Jumlah ini didapatkan dari perwakilan ICTA yang ada di setiap provinsi.

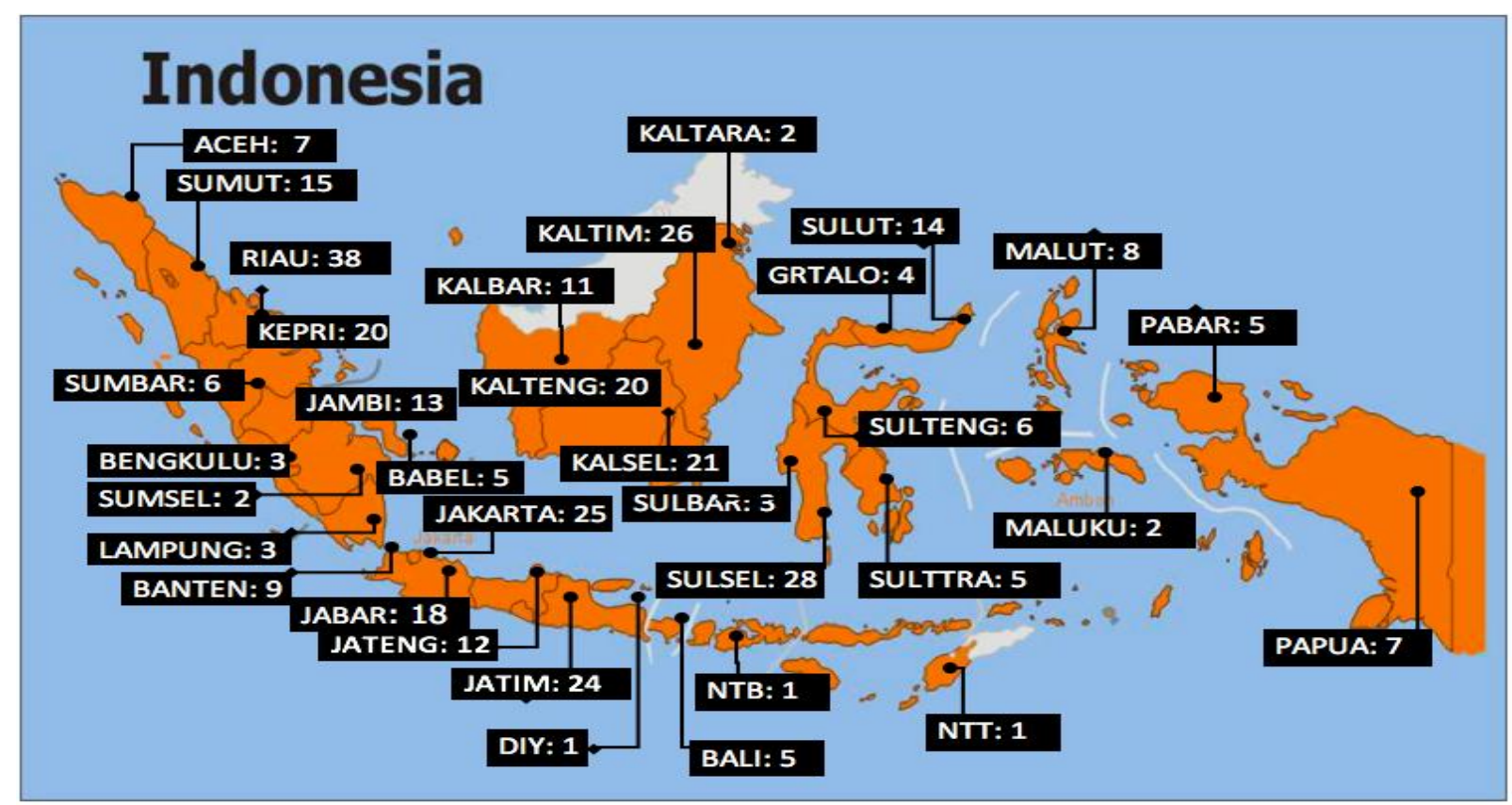

Sumber: Komkeminfo (2016).

Gambar 1 Peta sebaran TV kabel lokal Indonesia yang telah memiliki Izin Penyelenggaraan Penyiaran (IPP) 
LPB TV kabel tersebut tersebar di seluruh wilayah Indonesia, dari ibukota provinsi hingga ke wilayah kecamatan bahkan sudah sampai ke pedesaan. Menurut data ICTA hingga September 2016, perusahaan TV kabel yang telah menjadi anggota ICTA per September 2016 berjumlah 177 perusahaan. Jumlah Cable TV Operator (CTO) di seluruh Indonesia jauh lebih banyak lagi, karena satu perusahaan atau perseroan terbatas bisa terdiri dari dua atau lebih CTO. Jadi beberapa CTO dapat bergabung dalam satu legalitas usaha.

Besar kecilnya usaha TV kabel lokal di antaranya dipengaruhi oleh pertumbuhan jumlah pelanggan, nilai iuran berlangganan, manajemen usaha, kepadatan hunian, kondisi perekonomian, dan kondisi sosial wilayah tersebut (ICTA 2015). Bisnis TV kabel mengalami pertumbuhan nyata terutama pada daerah atau wilayah dengan tingkat perekonomian baik dan kepadatan hunian yang tinggi. Harga berlangganan yang relatif murah menjadikan TV kabel banyak diminati masyarakat yang berada di kota kecil atau pelosok daerah. Setiap kota atau wilayah di Indonesia memiliki kondisi sosial dan ekonomi berbeda-beda yang berdampak pada jalannya suatu usaha TV kabel. Menjamurnya usaha TV kabel yang tersebar di seluruh wilayah Indonesia menjadi potensi luar biasa untuk bisa dikembangkan menjadi sebuah kekuatan besar, jika dikelola dengan baik. Ada satu benang merah yang dapat menyatukan seluruh CTO lokal di Indonesia, yaitu bahwa setiap TV kabel masih bergantung kepada pihak ketiga untuk mendukung content siaran premiumnya. Kontrak content premium kepada produsen content favorit seperti HBO dan FOX, tidak dapat dilakukan secara sendiri-sendiri oleh CTO, karena harganya sangat mahal dan persyaratanya rumit. Persaingan dalam industri media televisi tidak hanya terjadi pada televisi nasional, namun juga pada TV berlangganan dan TV kabel.

PT DKM merupakan perusahaan yang bergerak di bidang jasa pelayanan penyiaran berlangganan melalui media kabel, yang biasa disebut TV kabel, berbadan hukum tetap berbentuk perseroan terbatas yang berdiri pada Desember 2011 di Kota Payakumbuh. Produk yang dijual hanya berupa layanan siaran televisi. Kota Payakumbuh merupakan salah satu kota dengan jumlah penduduk terbesar di luar ibukota Provinsi Sumatera Barat. Berdasarkan data BPS (2017), jumlah penduduk Kota Payakumbuh tahun 2016 berjumlah 129.807 jiwa dan pertumbuhan ekonomi yang relatif baik yakni 6,08 persen pada tahun 2016

Setiap industri mempunyai potensi berbeda secara fundamental. Pengaruh yang begitu kuat dari struktur industri dalam menentukan aturan persaingan sehingga menjadikan industri sebagai aspek utama dari lingkungan perusahaan sebagai tempat suatu perusahaan bersaing. Kondisi persaingan antara perusahaan dalam suatu industri dipengaruhi oleh lima kekuatan yang dikenal sebagai Five Forces Model oleh Porter (2004). Kekuatan tersebut meliputi ancaman pendatang baru, kekuatan tawar-menawar pembeli, kekuatan tawar-menawar pemasok, ancaman produk pengganti, dan persaingan antar perusahaan yang ada.

Tingginya persaingan di industri TV berbayar mengharuskan perusahaan memiliki suatu strategi dalam meningkatkan daya saingnya untuk mempertahankan keberadaan usahanya dan memenangkan persaingan. Dalam mempertahankan bisnisnya, PT DKM telah melakukan berbagai langkah untuk menarik minat pelanggan dan mempertahankan posisinya di bisnis TV berbayar, yaitu menjual produk siaran content premium dan membuat content lokal. Penambahan beberapa channel premium telah dilakukan perusahaan berupa channel olah raga dan film. Usaha yang telah dilakukan tersebut tidak optimal, karena belum menyentuh akar permasalahan seperti mutu gambar yang belum maksimal, keterbatasan jumlah channel premium favorit, dan masalah infrastruktur tiang tumpuh.

Salah satu usaha yang dilakukan PT DKM agar tetap mempertahankan jumlah pelanggan adalah dengan terus menjaga mutu siaran, walaupun masih menggunakan teknologi analog atau sistem manual, dimana mutu gambar dan suara belum sebaik teknologi digital. Untuk menjaga agar kualitas gambar tetap stabil hingga ke rumah pelanggan, perusahaan secara berkala melakukan maintainance terhadap alat pendukung outdoor. Walaupun usaha yang dilakukan perusahaan masih belum maksimal, tetapi perusahaan terus melakukan perbaikan layanan dan siaran agar tetap menjadi pemimpin pasar. Berdasarkan data internal PT DKM, jangkauan jaringan dan pelanggan TV kabel telah mencapai $40 \%$ dari luas wilayah pemukiman Kota Payakumbuh dengan jumlah pelanggan 3.037 di tahun 2016. Sebagai pemimpin pasar dalam industri TV berbayar di Payakumbuh, PT DKM harus tetap mewaspadai pesaingnya (Tabel 1). Posisi PT DKM 
sebagai pemimpin pasar dalam industri TV berbayar belum menunjukkan PT DKM sebagai perusahaan kuat yang dapat memenangkan persaingan dalam jangka panjang. Oleh sebab itu, strategi peningkatan daya saing TV kabel lokal PT DKM perlu dianalisis untuk memenangkan persaingan pada industri TV berbayar di Kota Payakumbuh. Berdasarkan permasalahan tersebut, maka judul yang diteliti adalah "Strategi Peningkatan Daya Saing TV Kabel Lokal", dengan tujuan penelitian: (1) Menganalisis kondisi persaingan PT DKM dalam industri TV berbayar di Kota Payakumbuh; (2) Menganalisis faktorfaktor internal dan eksternal PT DKM yang diprioritaskan; (3) Merumuskan strategi alternatif yang dapat diimplementasikan PT DKM untuk meningkatkan daya saingnya.

Tabel 1. TV berbayar di Kota Payukumbuh 2016

\begin{tabular}{lllc}
\hline No & \multicolumn{1}{c}{ Perusahaan } & Produk & $\begin{array}{c}\text { Jumlah } \\
\text { Pelanggan }\end{array}$ \\
\hline 1 & PT DKM & DKM & 3.037 \\
2 & PT Telkom Indonesa & Indihome & 1.500 \\
3 & PT Mega Media & Orange & 500 \\
& Indonesia & TV & \\
4 & $\begin{array}{l}\text { PT Irama Mitra } \\
\text { Media }\end{array}$ & IMM & 250 \\
\hline
\end{tabular}

\section{METODE PENELITIAN}

Penelitian ini membutuhkan jenis data primer dan sekunder. Data primer diperoleh melalui observasi, kuesioner, dan wawancara mendalam. Responden terdiri dari tujuh pakar yang berasal dari pimpinan perusahaan, Komisi Penyiaran Indonesia Daerah Sumatera Barat, Kementerian Komunikasi dan Informatika, asosiasi TV kabel Indonesia (ICTA) dan pelanggan terpilih untuk mengetahui kondisi persaingan dan faktorfaktor internal dan eksternal yang memengaruhi PT DKM dalam menghadapi persaingan di industri TV berlangganan di Kota Payakumbuh. Kuesioner yang diberikan kepada responden berisi pertanyaan tertutup. Pertanyaan yang diajukan memuat alternatif jawaban yang telah disediakan, sehingga responden hanya memilih salah satu alternatif jawaban yang dianggap paling sesuai.

Data sekunder yang dibutuhkan dalam penelitian ini adalah data internal PT DKM dan data perkembangan usaha TV berbayar di Kota Payakumbuh, data tentang regulasi TV berbayar, serta data lainnya yang dianggap perlu. Berbagai data sekunder lainnya yang dibutuhkan dalam penelitian ini diperoleh dari dokumen perusahaan, pemerintah yang dalam hal ini Komisi Penyiaran Indonesia (KPI) dan Kementerian Komunikasi dan Informatika (Kemkominfo), serta dokumen asosiasi TV kabel Indonesia (ICTA).

Responden internal perusahaan dan eksternal (pakar) ditentukan dengan cara dipilih secara sengaja berdasarkan pertimbangan pengetahuan, pengalaman, dan kemampuan dalam bidang yang diteliti. Responden diambil dengan menggunakan teknik pengambilan contoh tanpa peluang (non probability sampling) dengan penentuan secara sengaja (purposive sampling) melalui pendekatan expertise judgement.

\section{Pengolahan dan Analisis Data}

Penelitian ini menggunakan teknik pengolahan data terdiri atas tiga tahap, yaitu tahap masukan (input stage), tahap pencocokan (matching stage), dan tahap keputusan (decision stage). Data yang diperoleh dari metode deskriptif tersebut, dilanjutkan dengan analisis persaingan dalam industri menggunakan model Porter's Five Forces. Analisis faktor prioritas dengan matriks IFE (Internal Factor Evaluation), matriks EFE (External Factor Evaluation), dan matriks SWOT (Strength Weaknesses, Opportunities and Threats) (David 2013). Untuk tahap keputusan dilakukan dengan menggunakan matriks ANP (Analytic Network Process).

Analisis persaingan industri digunakan untuk menganalisis dan mengidentifikasi kondisi persaingan dalam industri TV berbayar yang ada di Kota Payakumbuh, sehingga PT DKM dapat mengambil langkah strategik untuk meningkatkan daya saingnya. Five force model of Porter digunakan sebagai acuan teoritis dalam analisis persaingan industri yang terdiri dari masuknya pendatang baru, ancaman produk pengganti, kekuatan tawar-menawar pemasok, kekuatan tawar-menawar pembeli, dan persaingan di antara pesaing dalam industri (Porter 2004).

Analisis faktor internal mempunyai tujuan mengidentifikasi kekuatan dan kelemahan utama yang menjadi fondasi bagi PT DKM dalam menyusun strategi peningkatan daya saing di industri TV berbayar/berlangganan. Analisis faktor eksternal berupa analisis terhadap lingkungan eksternal diidentifikasi oleh faktor peluang dan ancaman yang dihadapi perusahaan (David 2013). Faktor internal dan eksternal tersebut kemudian diformulasikan ke dalam 
Matriks IFE dan EFE. Berbagai alternatif strategi yang akan diterapkan dan kemudian dirumuskan dengan menggunakan matriks SWOT. Tujuan analisis SWOT untuk mengidentifikasi alternatifalternatif strategi secara intuitif yang dapat dan sesuai untuk dilaksanakan. Matriks ini menghasilkan empat tipe alternatif strategi, yaitu SO, ST, WO, dan WT (David, 2013).

ANP merupakan hasil pengembangan dari metode Analytic Hierarcy Process (AHP). Adanya saling keterkaitan anatar peubah dalam bentuk interaksi dan umpan balik (feedback) dari unsurunsur dalam klaster (inner dependence) atau antar klaster (outer dependence) telah mampu diakomodasi dalam metode ini (Saaty, 1999). Analisis SWOT memiliki kekurangan dalam ukuran pengukuran dan evaluasi, sehingga perlu dilakukan suatu bentuk analisis ANP yang mengukur dan memperhitungkan kemungkinan ketergantungan antar faktor. ANP memungkinkan pengukuran ketergantungan antara faktor strategik yang didasarkan pada independensi antara faktor-faktor yang ada (Yuksel dan Dagdeviren, 2007). Network merupakan struktur dari ANP karena memiliki feedback, sementara struktur AHP adalah hirarki tanpa adanya umpan balik diantara peubah. Gambar 2 memperlihatkan perbedaan struktur AHP dan ANP (Azis, 2003).

Pendekatan ANP tidak bergantung pada pada kemampuan berargumentasi secara logis, namun feeling dan intuisi merupakan yang paling penting dalam mengambil keputusan atau kesimpulan (Saaty, 2013). Pendekatan dengan metode ANP lebih akurat, karena dapat mengelola masalah kompleks yang berhubungan dengan ketergantungan dan feedback. ANP memberikan bobot dalam pemilihan strategi peningkatan daya saing PT DKM.

\section{HASIL DAN PEMBAHASAN}

\section{Analisis Kondisi Persaingan PT DKM}

Eksistensi suatu perusahaan harus dipertahankan dengan cara peningkatan daya saing ditengah persaingan bisnis yang semakin ketat dan situasi pasar semakin dinamis. Kemampuan berkompetisi suatu badan usaha dapat dilihat dari daya saingnya dengan memanfaatkan keunggulan-keunggulan yang dimilikinya. Daya saing suatu organisasi ditentukan oleh kemampuan perusahaan membuat inovasi dan meningkatkan kemampuannya (Porter, 2004). Pengusaha yang optimis akan menghargai potensi partumbuhan dari posisi terakhir persaingan dan yang pesimis akan beranggapan bahwa posisi tersebut sebagai hambatan komersial berupa rendahnya tingkat pengembalian, faktor risiko, tingginya tingkat profesionalisme yang diminta dari para pemain (Grigore, 2014).

Analisis terhadap persaingan bertujuan mengetahui tingkat persaingan yang dihadapi perusahaan dalam industri dengan menganalisis peubah yang mengacu pada teori Porter'sFive Forces. Pesaing bukan hanya berupa pesaing langsung perusahaan, tetapi juga pesaing potensial seperti perusahaan yang akan masuk, para pemasok, para konsumen, dan para produsen produk pengganti.

Hasil analisis menunjukkan peubah yang memiliki pengaruh paling kuat dengan kategori sedang terhadap kondisi persaingan PT. DKM adalah ancaman pendatang baru, kemudian ancaman antar perusahaan, kekuatan tawarmenawar pemasok, ancaman produk subtitusi dan yang memiliki skor terkecil adalah kekuatan tawar menawar pembeli (Tabel 2).

\section{Jaringan Feedback}
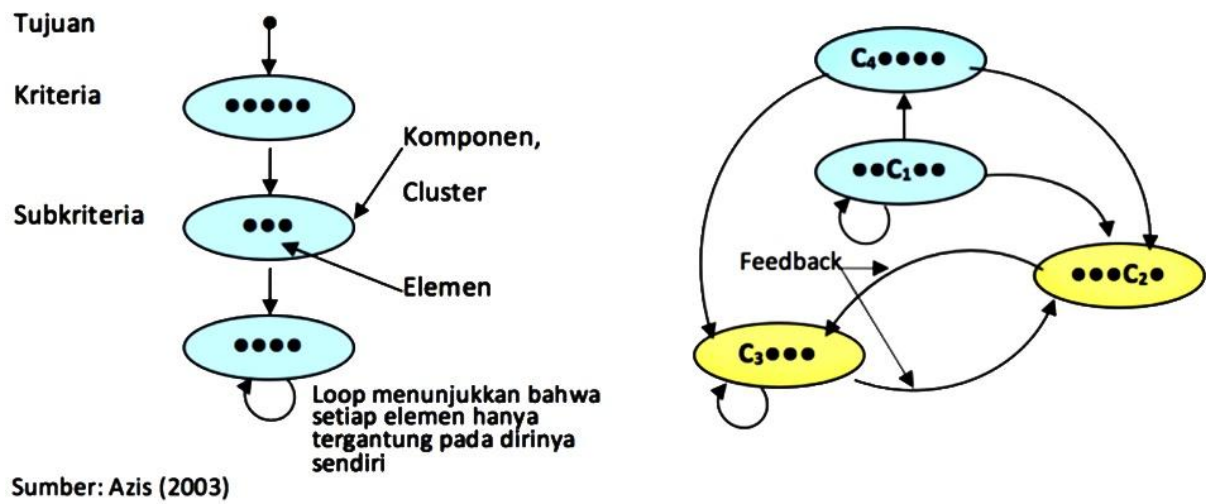

Gambar 2. Perbedaan antara AHP dan ANP 
Strategi yang dilakukan oleh PT DKM saat ini dalam menghambat masuknya pendatang baru, yaitu memaksimalkan layanan content lokal produksi internal perusahaan sementara masih terdapat masalah pada content siaran premium yang belum terselesaikan. Lemahnya strategi yang digunakan perusahaan menyebabkan posisi PT DKM di industri TV berbayar di Kota Payakumbuh sangat rentan terhadap ancaman pendatang baru.

Kota Payakumbuh merupakan area blank spot dimana siaran TV hanya bisa diperoleh masyarakat setempat dengan menggunakan antena parabola atau berlangganan dengan TV berbayar. Kondisi ini sangat menguntungkan bagi para operator TV berbayar. Hasil analisis menunjukkan dimana bisnis TV berbayar di Kota Payakumbuh, ancaman pendatang baru memiliki kategori sedang dengan nilai skor tertinggi $(2,87)$ merupakan peubah yang cukup menjadi ancaman bagi PT DKM (Tabel 2). Peubah ini harus menjadi perhatian serius bagi PT DKM untuk memenangkan persaingan TV berbayar di Kota Payakumbuh.

Tabel 2. Penilaian analisis industri

\begin{tabular}{ccccc}
\hline No & \multicolumn{1}{c}{ Variabel } & Skor & Kategori & Rank \\
\hline 1 & $\begin{array}{l}\text { Ancaman pendatang } \\
\text { baru }\end{array}$ & 2.87 & Sedang & 1 \\
2 & $\begin{array}{l}\text { Ancaman antar } \\
\text { perusahan }\end{array}$ & 2.64 & Sedang & 2 \\
3 & $\begin{array}{l}\text { Kekuatan tawar- } \\
\text { menawar pemasok } \\
4\end{array}$ & 2.59 & Sedang & 3 \\
5 & $\begin{array}{l}\text { Ancaman produk } \\
\text { subtitusi } \\
\text { Kekuatan tawar- } \\
\text { menawar pembeli }\end{array}$ & 2.18 & Sedang & 4 \\
\hline
\end{tabular}

\section{Evaluasi Faktor Internal dan Eksternal PT DKM}

\section{Analisis Matriks IFE}

Matriks IFE disusun berdasarkan faktor strategi internal perusahaan seperti kekuatan dan kelemahan yang dimiliki perusahaan tersebut. Penilaian terhadap kekuatan dan kelemahan dilaksanakan oleh pakar yang mengerti kondisi internal perusahaan. Hasil analisis matriks IFE PT DKM dapat diuraikan pada Tabel 3 yang diperoleh dari hasil evaluasi dengan responden internal perusahaan.

Pada Tabel 3 dapat dilihat bahwa kekuatan paling dominan yang dimiliki perusahaan adalah harga berlangganan sangat kompetitif dibandingkan pesaing dengan skor 0,419 . Kelemahan nyata yang ada pada perusahaan adalah kurangnya jumlah channel favorit dengan skor 0,136. Hasil total skor terbobot PT DKM adalah 2,449, menunjukkan perusahaan memiliki posisi internal belum kuat dengan skor di bawah 2,50. Dalam hal ini, perusahaan belum mampu memaksimalkan kekuatan yang ada dan belum mampu mengatasi kelemahan yang dimiliki.

Tabel 3. Matriks IFE PT DKM

\begin{tabular}{|c|c|c|c|}
\hline Faktor Strategis Internal & $\begin{array}{l}\text { Bobot } \\
\text { (a) }\end{array}$ & $\begin{array}{c}\text { Rank } \\
\text { (b) }\end{array}$ & $\begin{array}{l}\text { Skor } \\
(\mathrm{axb}) \\
\end{array}$ \\
\hline \multicolumn{4}{|l|}{ KEKUATAN } \\
\hline $\begin{array}{l}\text { - Jumlah pelanggan cukup } \\
\text { besar }\end{array}$ & 0,088 & 4 & 0,327 \\
\hline $\begin{array}{l}\text { - Telah menjadi market } \\
\text { leader di Kota }\end{array}$ & 0,099 & 3 & 0,340 \\
\hline Payakumbuh & & & \\
\hline $\begin{array}{l}\text { - Harga berlangganan } \\
\text { sangat kompetitif } \\
\text { dibanding pesaing }\end{array}$ & 0,108 & 4 & 0,416 \\
\hline - Memiliki channel lokal & 0,077 & 3 & 0,264 \\
\hline - Memiliki teknisi handal & 0,095 & 4 & 0,367 \\
\hline \multicolumn{4}{|l|}{ KELEMAHAN } \\
\hline $\begin{array}{l}\text { - Kurangnya kinerja tena- } \\
\text { ga pemasar perusahaan }\end{array}$ & 0,086 & 2 & 0,147 \\
\hline $\begin{array}{l}\text { - Kurangnya promosi dari } \\
\text { perusahaan }\end{array}$ & 0,083 & 2 & 0,155 \\
\hline $\begin{array}{l}\text { - Terbatasnya jumlah } \\
\text { channel favorit }\end{array}$ & 0,119 & 1 & 0,136 \\
\hline $\begin{array}{l}\text { - Mutucontent siaran dan } \\
\text { gambar belum maksimal } \\
\text { - Masih menggunakan } \\
\text { tiang PLN sebagai tiang }\end{array}$ & 0,125 & 1 & 0,142 \\
\hline tumpu kabel & 0,120 & 1 & 0,154 \\
\hline Total & 1,000 & & 2,449 \\
\hline
\end{tabular}

\section{Analisis Matriks EFE}

Faktor strategi eksternal berupa peluang dan ancaman digunakan sebagai dasar menyusun matriks EFE. Penilaian terhadap peluang dan ancaman perusahaan sebagai faktor eksternal dilakukan oleh pakar yang memahami kondisi eksternal perusahaan. Metode yang digunakan untuk menentukan bobot adalah metode pairwise comparision. Hasil analisis matriks EFE PT DKM dapat di lihat pada Tabel 4 .

Pada Tabel 4 terlihat bahwa peluang utama yang dimiliki oleh PT DKM adalah banyaknya penyedia content TV kabel dengan skor 0,332. Ancaman yang paling nyata yang dialami perusahaan adalah semakin bertambahnya pesaing dengan skor 0,312. Penelitian yang dilakukan Sunardi (2012) menyebutkan bahwa tantangan terbesar PT Telkom adalah persaingan yang semakin ketat di bisnis telekomunikasi. Total 
hasil skor terbobot untuk matriks EFE adalah 2,928 menggambarkan perusahaan berada pada posisi eksternal sedang, dimana kemampuan merespon perubahan atau memanfaatkan peluang untuk mengatasi ancaman masih pada tingkat rataan.

Tabel 4. Matriks EFE PT DKM

\begin{tabular}{|c|c|c|c|}
\hline Faktor Strategis Eksternal & $\begin{array}{c}\text { Bobot } \\
\text { (a) }\end{array}$ & $\begin{array}{c}\text { Rank } \\
\text { (b) }\end{array}$ & $\begin{array}{l}\text { Skor } \\
(\mathrm{axb})\end{array}$ \\
\hline \multicolumn{4}{|l|}{ PELUANG } \\
\hline $\begin{array}{l}\text { - Kebutuhan masyarakat } \\
\text { akan hiburan semakin } \\
\text { meningkat }\end{array}$ & 0,088 & 4 & 0,315 \\
\hline $\begin{array}{l}\text { - Semakin berkembang- } \\
\text { nya teknologi TV kabel }\end{array}$ & 0,078 & 3 & 0,222 \\
\hline $\begin{array}{l}\text { - Pertumbuhan ekonomi } \\
\text { masyarakat Payakum- } \\
\text { buh terus meningkat }\end{array}$ & 0,079 & 4 & 0,292 \\
\hline $\begin{array}{l}\text { - Content premium favorit } \\
\text { sebagian besar berasal } \\
\text { dari pesaing }\end{array}$ & 0,098 & 3 & 0,309 \\
\hline $\begin{array}{l}\text { - Banyaknya penyedia } \\
\text { content TV kabel }\end{array}$ & 0,106 & 3 & 0,332 \\
\hline $\begin{array}{l}\text { - Dukungan positif dari } \\
\text { pemerintah Kota } \\
\text { Payakumbuh }\end{array}$ & 0,104 & 3 & 0,312 \\
\hline \multicolumn{4}{|l|}{ ANCAMAN } \\
\hline $\begin{array}{l}\text { - Semakin bertambahnya } \\
\text { pesaing }\end{array}$ & 0,104 & 3 & 0,312 \\
\hline $\begin{array}{l}\text { - Akses dan biaya } \\
\text { teknologi internet yang } \\
\text { semakin murah }\end{array}$ & 0,111 & 3 & 0,286 \\
\hline $\begin{array}{l}\text { - Semakin banyaknya } \\
\text { promosi menarik dari } \\
\text { pesaing }\end{array}$ & 0,112 & 2 & 0,256 \\
\hline - Hadirnya pesaing kuat & 0,121 & 2 & 0,293 \\
\hline Total & 1,000 & & 2,928 \\
\hline
\end{tabular}

\section{Analisis Matriks IE (Internal-Eksternal)}

Hasil analisis evaluasi faktor strategi PT DKM dari faktor internal berupa kekuatan dan kelemahan menunjukkan total nilai IFE 2,449 dan faktor eksternal berupa peluang dan ancaman diperoleh total nilai EFE 2,928. Matriks IE membantu dalam menentukan posisi PT DKM di industri TV berbayar di Kota Payakumbuh.

Berdasarkan hasil analisis matriks IE, PT DKM berada pada posisi sel $\mathrm{V}$ seperti pada Gambar 3. Hal ini menunjukkan PT DKM berada di kategori bertahan dan menjaga (hold and maintain). Strategi yang paling sesuai untuk diterapkan adalah strategi pengembangan produk dan penetrasi pasar.

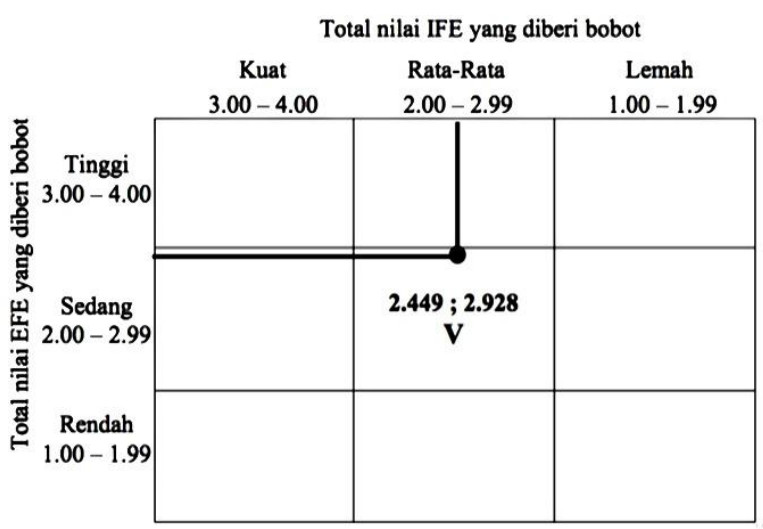

Gambar 3. Matriks IE PT DKM

\section{Perumusan Strategi Peningkatan Daya Saing PT DKM}

Analisis SWOT digunakan untuk merumuskan alternatif-alternatif strategi yang akan digunakan untuk meningkatkan daya saing PT DKM. Dengan matriks SWOT, kekuatan dan peluang yang dimiliki perusahaan dimaksimalkan, sementara kelemahan dan ancaman yang ada diminimalkan untuk menghasilkan beberapa alternatif strategi yang tepat dan dapat diimplementasikan oleh perusahaan. Terdapat empat kombinasi strategi yang dihasilkan oleh matriks SWOT, yaitu Strategi Strengthness-Opportunities (SO), Strategi Weaknesses-Opportunities (WO), Strategi Strengthness-Threats (ST), dan Strategi Weaknesses-Threats (WT). Keempat kombinasi strategi tersebut menghasilkan alternatif strategi bagi PT DKM. Alternatif strategi yang dihasilkan dari analisis matriks SWOT dapat dilihat pada Gambar 4.

\section{Strategi SO}

Kombinasi kekuatan dan peluang yang berasal dari eksternal perusahaan menghasilkan dua alternatif strategi. Alternatif strategi peningkatan daya saing PT DKM yang memanfaatkan kekuatan perusahaan dan peluang dari luar fokus pada inovasi produk (S1, S2, S4, S5, O1, O2, O3, O6) dan meningkatkan kerjasama dengan content provider terbaik dan pemerintah setempat (S1, S2, S4, O4, O5).

Inovasi produk merupakan strategi yang tepat untuk diimplementasikan oleh PT DKM saat ini. Jumlah pelanggan besar, posisi sebagai market leader, memiliki channel lokal dan memiliki teknisi handal menjadi kelebihan perusahaan untuk mendukung strategi ini. Peluang yang ada berupa meningkatnya kebutuhan masyarakat akan hiburan, berkembangnya teknologi TV kabel, dan pertumbuhan ekonomi masyarakat Payakumbuh yang semakin meningkat. Saat ini PT DKM hanya 
menjual produk berupa channel TV premium kepada pelanggannya. Masih banyak peluang yang berasal dari eksternal yang bisa diambil untuk meningkatkan daya saing perusahaan, di antaranya dengan menjual produk internet kepada pelanggan selain channel premium. Perkembangan teknologi di bidang telekomunikasi, termasuk internet yang begitu pesat sudah dirasakan oleh masyarakat di daerah kota kecil seperti Kota Payakumbuh. Internet sudah menjadi gaya hidup masyarakat dunia, tidak hanya yang berada di kota besar, tetapi juga masyarakat yang berada di daerah. Produk internet bisa diperoleh dengan cara menjalin kerja sama dengan operator internet yang semakin banyak bermunculan dengan penawaran harga lebih kompetitif. Inovasi materi pada channel lokal dapat memberikan keuntungan tersendiri bagi PT DKM.

Strategi lain yang bisa diimplementasikan oleh PT DKM dengan memanfaatkan kekuatan dan peluang yang ada dengan meningkatkan kerjasama dengan content provider terbaik dan kerjasama dengan pemerintah setempat. Kekuatan yang dimiliki perusahaan berupa jumlah pelanggan yang besar, telah menjadi market leader, dan adanya channel lokal, serta peluang yang ada berupa content premium sebagian besar berasal dari pesaing, banyaknya penyedia content TV kabel dan adanya dukungan positif dari pemerintah Kota Payakumbuh merupakan modal yang cukup bagi PT DKM untuk bisa menjalankan strategi ini. Kerjasama dengan contentprovider yang tepat dapat memberikan keuntungan tersendiri bagi perusahaan, yaitu mutucontent siaran yang lebih bermutu dengan penawaran harga lebih kompetitif. Hubungan kerjasama dengan pemerintah setempat yang saat ini sudah mulai terjalin perlu ditingkatkan dengan memanfaatkan channel lokal yang telah dimiliki, agar keberadaan PT DKM di Kota Payakumbuh bisa lebih kuat.

\section{StrategiWO}

Alternatif strategi WO diformulasikan dengan meminimalkan kelemahan perusahaan untuk memperoleh kesempatan yang ada di luar perusahaan. Gabungan strategi WO menghasilkan alternatif strategi pengembangan produk, yaitu menambah channel premium favorit (W3, W4, O1, $\mathrm{O} 2, \mathrm{O} 4, \mathrm{O} 5)$.

Jumlah channel premium yang dimiliki PT. DKM saat ini 17 channel dari 38 total channel yang disiarkan. Jumlah ini masih kurang jika dibandingkan dengan jumlah channel yang disiarkan oleh pesaing yang berjumlah lebih dari 200 channel premium. Mutucontent siaran dan gambar yang dimiliki PT DKM saat ini juga belum maksimal jika dibandingkan dengan content siaran pesaing. Kebutuhan masyarakat akan hiburan semakin meningkat, semakin berkembangnya teknologi TV kabel, content premium yang disiarkan berasal dari pesaing dan banyaknya penyedia content TV kabel merupakan peluang yang bisa diambil oleh PT DKM untuk menambah channel premium favorit.

\section{Strategi ST}

Gabungan kekuatan yang ada pada perusahaan dengan ancaman dari luar menghasilkan sebuah alternatif strategi yang bisa diaplikasikan oleh PT DKM. Alternatif strategi ST berupa penetrasi pasar, yakni meningkatkan mutu pelayanan dan penanganan yang cepat dibanding pesaing (S1, S5, T1, T3, T4).

Pelayanan mudah, cepat, responsif dan keramahan yang ditunjukkan melalui sikap dan tindakan langsung kepada konsumen merupakan nilai positif yang harus ditingkatkan oleh PT DKM kepada pelanggannya. Jumlah pelanggan yang cukup besar dan memiliki teknisi handal merupakan modal kekuatan yang dimiliki perusahaan menghadapi ancaman yang ada, seperti semakin bertambahnya pesaing, banyaknya promosi yang menarik dari pesaing, dan hadirnya pesaing yang kuat.

\section{Strategi WT}

Alternatif strategi WT dirumuskan dengan mengurangi kelemahan yang dimiliki perusahaan dan menghindari ancaman yang datang dari luar. Ada beberapa alternatif strategi yang dihasilkan dari formulasi ini, yaitu melakukan kegiatan pemasaran yang lebih insentif dan meningkatkan kinerja pemasar, upgrade teknologi, membuat promosi khusus kepada pelanggan dan masyarakat, serta investasi infrastruktur dengan membuat tiang tumpu kabel sendiri.

Kurangnya kinerja tenaga pemasar perusahaan dan kurangnya promosi dari perusahaan merupakan kelemahan yang harus dibenahi oleh PT DKM dengan cara melakukan kegiatan pemasaran lebih intensif dan meningkatkan kinerja tenaga pemasar (W1, W2, T1, T3, T4). Strategi ini untuk menghadapi ancaman yang ada, seperti semakin bertambahnya pesaing, semakin 
meningkatnya promosi yang lebih menarik oleh pesaing dan kehadiran pesaing yang kuat.

Kelemahan lain yang dimilik PT DKM adalah kurangnya jumlah channel favorit dan belum maksimalnya mutu siaran dan gambar. Strategi yang tepat untuk mengatasi kelemahan dengan melakukan upgrade teknologi TV kabel (W3, W4, T1, T2, T4). Saat ini, PT DKM masih menggunakan teknologi analog yang menghasilkan mutu gambar dan suara yang belum maksimal, sementara pesaing sebagian besar telah memakai teknologi digital dengan mutu gambar dan suara yang jernih. Upgrade teknologi ini dilakukan untuk menghadapi ancaman yang ada berupa akses dan biaya teknologi internet yang semakin murah, bertambahnya pesaing, termasuk kehadiran pesaing yang kuat.

Kurangnya promosi yang dilakukan perusahaan merupakan kelemahan yang bisa diatasi dengan cara membuat promosi khusus kepada pelanggan dan masyarakat (W2, T1, T3, T4).
Strategi ini dapat menghadapi ancaman yang berasal dari luar, seperti semakin banyaknya promosi yang menarik dari pesaing dan bertambahnya pesaing termasuk kehadiran pesaing yang kuat.

Kelemahan lain yang dimiliki perusahaan adalah PT DKM masih menggunakan tiang PLN sebagai tiang tumpu kabel. Ketergantungan dengan pihak lain dalam hal infrastruktur jaringan dapat membahayakan keberadaan PT DKM di Kota Payakumbuh, di mana sewaktuwaktu pihak PLN atau perusahaan lain yang ditunjuk (Icon Plus) tidak mengizinkan pihak ketiga menggunakan tiang tersebut. Solusi untuk mengatasi kelemahan ini dengan strategi investasi infrastruktur menggunakan tiang tumpu kabel sendiri (W5, T1, T2, T4). Strategi ini membutuhkan biaya yang tidak sedikit, karena tiang yang digunakan jumlahnya cukup banyak, dimana jarak antara satu tiang dengan tiang lainnya berjarak $50 \mathrm{~m}$.

\begin{tabular}{|c|c|c|}
\hline Faktor Eksternal & $\begin{array}{l}\text { Kekuatan (S) } \\
\text { 1. Jumlah pelanggan cukup } \\
\text { besar } \\
\text { 2. Telah menjadi market leader } \\
\text { di kota Payakumbuh } \\
\text { 3. Harga sangat kompetitif } \\
\text { dibanding pesaing } \\
\text { 4. Memiliki channel lokal } \\
\text { 5. Memiliki teknisi handao }\end{array}$ & $\begin{array}{l}\text { Kelemahan (W) } \\
\text { 1. Kurangnya kinerja tenaga pemasar } \\
\text { perusahaan } \\
\text { 2. Kurangnya promosi dari } \\
\text { perusahaan } \\
\text { 3. Terbatasnya jumlah channel favorit } \\
\text { 4. Mutu content siaran dan gambar } \\
\text { belum maksimal } \\
\text { 5. Masih menggunakan tiang PLN } \\
\text { sebagai tiang tumpu kabel }\end{array}$ \\
\hline $\begin{array}{l}\text { Peluang (O) } \\
\text { 1. Kebutuhan masyarakat akan hiburan } \\
\text { semakin meningkat } \\
\text { 2. Semakin berkembangnya teknologi TV } \\
\text { kabel } \\
\text { 3. Pertumbuhan ekonomi masyarakat } \\
\text { Payakumbuh terus meningkat } \\
\text { 4. Content premium favorit sebagian besar } \\
\text { berasal dari pesaing } \\
\text { 5. Banyaknya penyedia content TV kabel } \\
\text { 6. Dukungan positif dari pemerintah Kota } \\
\text { Payakumbuh }\end{array}$ & \begin{tabular}{ll}
\multicolumn{1}{c}{ Strategi SO } \\
1. & Inovasi produk (S1, S2, S4, \\
S5, O1, O2, O3, O6) \\
2. \\
Meningkatkan kerjasama \\
dengan content provider \\
terbaik (S1, S2, S4, O4, O5)
\end{tabular} & $\begin{array}{l}\text { Strategi WO } \\
\text { Menambah channel premium favorit } \\
(\mathrm{W} 3, \mathrm{~W} 4, \mathrm{O} 1, \mathrm{O} 2, \mathrm{O} 4, \mathrm{O} 5)\end{array}$ \\
\hline $\begin{array}{l}\text { Ancaman (T) } \\
\text { 1. Semakin bertambahnya pesaing } \\
\text { 2. Akses dan biaya teknologi internet yang } \\
\text { semakin murah dan mudah dijangkau } \\
\text { masyarakat } \\
\text { 3. Semakin banyaknya promosi menarik } \\
\text { dari pesaing } \\
\text { 4. Hadirnya pesaing kuat }\end{array}$ & \begin{tabular}{l}
\multicolumn{1}{c}{ Strategi ST } \\
Meningkatkan mutu pelayanan \\
dan penanganan cepat \\
dibanding pesaing (S1, S2, S5, \\
$\mathrm{T} 1, \mathrm{~T} 3, \mathrm{~T} 4)$
\end{tabular} & \begin{tabular}{ll}
\multicolumn{1}{c}{ Strategi WO } \\
1. & $\begin{array}{l}\text { Melakukan kegiatan pemasaran } \\
\text { lebih intensif dan meningkatkan }\end{array}$ \\
kinerja tenaga pemasar (W1, W2, \\
T1, T3, T4) \\
2. Upgrade teknologi (W3, W4, T1, \\
T2, T4) \\
3. Membuat promosi khusus kepada \\
pelanggan dan masyarakat (W2, \\
T1, T3, T4) \\
Investasi infrastruktur dengan \\
membuat tiang tumpu kabel \\
sendiri (W5, T1, T2, T4)
\end{tabular} \\
\hline
\end{tabular}


Strategi pengembangan produk yang dapat diterapkan oleh PT DKM adalah inovasi produk, menambah channel premium favorit dan upgrade teknologi. Strategi penetrasi pasar yang bisa diterapkan oleh PT DKM dengan meningkatkan kerjasama dengan content provider dan pemerintah setempat, meningkatkan mutu pelayanan, menerapkan harga kompetitif, membuat promosi khusus, melakukan kegiatan pemasaran yang lebih intensif dan membuat tiang tumpuh sendiri.

\section{Prioritas Strategi Peningkatan Daya Saing PT DKM}

Analytic Network Process (ANP) merupakan metode dalam pengambilan keputusan dengan memprioritaskan strategi yang mempertimbangkan berbagai macam faktor pembuat keputusan yang ada pada matriks SWOT (Shojaei et al., 2013). Berdasarkan matriks SWOT diperoleh delapan alternatif strategi peningkatan daya saing PT DKM, kemudian dilakukan pemilihan prioritas strategi peningkatan daya saing perusahaan dengan metode ANP. Prioritas strategi diperoleh dari gabungan pendapat tujuh pakar yang memahami industri TV kabel atau TV berbayar yang berasal dari internal PT DKM, asosiasi TV kabel (ICTA), Kementerian Komunikasi dan Informatika, Komisi Penyiaran Indonesia Sumatera Barat, serta pelanggan.

Penentuan prioritas strategi peningkatan daya saing PT DKM menggunakan beberapa komponen yang diklasifikasikan dalam beberapa cluster, yaitu goal, aspek, masalah, dan strategi seperti pada Gambar 5. Setiap cluster terdiri atas unsur. Cluster "goal" merupakan tujuan yang ingin dicapai, cluster "aspek" terdiri dari aspek internal dan eksternal perusahaan. Cluster "masalah" terdiri empat masalah utama, dua masalah dari aspek internal dan dua masalah dari aspek eksternal. Empat masalah utama meliputi terbatasnya jumlah channel favorit, mutucontent siaran dan gambar masih belum maksimal, semakin bertambahnya pesaing dan hadirnya pesaing yang kuat. Sementara klaster "strategi"

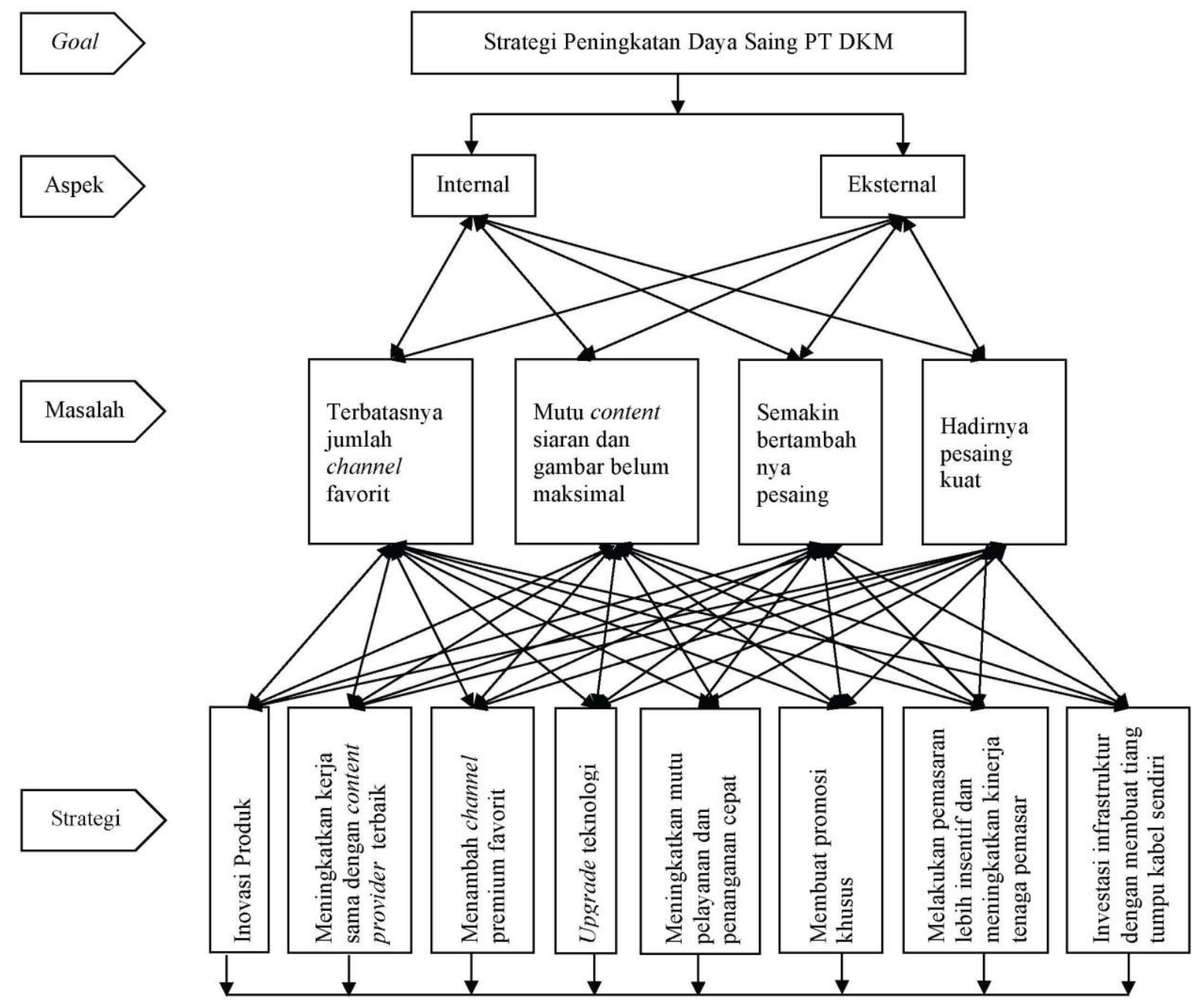

Gambar 5. Kerangka ANP strategi peningkatan daya daing PT DKM 
terdiri dari meningkatkan kerjasama dengan content provider dan pemerintah setempat, menambah channel premium favorit, upgrade teknologi, meningkatkan mutu pelayanan dan penanganan yang cepat dibanding pesaing, memberikan harga kompetitif untuk mempertahankan pasar yang sudah ada, membuat promosi khusus kepada pelanggan dan masyarakat, melakukan kegiatan pemasaran lebih intensif dan meningkatkan kinerja tenaga pemasar, serta melakukan kegiatan pemasaran yang lebih intensif, dan meningkatkan kinerja tenaga pemasar.

Cluster-cluster tersebut dibuat menjadi sebuah kerangka ANP dengan Software Superdecisions seperti pada Gambar 6. Penggunaan nama beberapa cluster disesuaikan dengan istilah yang ada pada softwaresuperdicions seperti cluster strategi diganti menjadi alternative agar proses sintetis dapat dikerjakan.

Prioritas strategi peningkatan daya saing PT DKM ditetapkan denganmatriks perbandingan berpasangan (pairwise comparison) yang melibatkan berbagai pihak yang memahami masalah industri TV kabel, baik praktisi/perusahaan, KPID, pemerintah dalam hal ini Kemkominfo, wakil asosiasi dan wakil pelanggan. Total jumlah responden dalam penelitian ini tujuh orang. Kuesioner pair-wise yang digunakan merupakan hasil modifikasi, dimana model kuesioner asli yang agak rumit disederhanakan dengan tujuan menjaga konsistensi jawaban responden dan mengurangi waktu yang dibutuhkan untuk wawancara (Ascarya, 2015). Data dari para pakar diolah dengansoftware Superdecions yang menghasilkan nilai masing-masing unsur yang ada di setiap cluster pada Tabel 5 .

Tabel 5. Hasil lengkap nilai setiap unsur pada setiap cluster

\begin{tabular}{|c|c|c|}
\hline No & Deskripsi & Nilai \\
\hline \multicolumn{3}{|c|}{ Aspek } \\
\hline 1 & Internal & 0,719 \\
\hline 2 & Eksternal & 0,281 \\
\hline \multicolumn{3}{|c|}{ Masalah } \\
\hline 1 & Terbatasnya jumlah channel favorit & 0,563 \\
\hline 2 & $\begin{array}{l}\text { Mutu content siaran dan gambar } \\
\text { belum maksimal }\end{array}$ & 0,437 \\
\hline 3 & Semakin bertambahnya pesaing & 0,245 \\
\hline 4 & Hadirnya pesaing kuat & 0,755 \\
\hline \multicolumn{3}{|c|}{ Strategi alternatif } \\
\hline 1 & Inovasi produk & 0,117 \\
\hline 2 & $\begin{array}{l}\text { Meningkatkan kerjasama dengan } \\
\text { content provider terbaik }\end{array}$ & 0,160 \\
\hline 3 & Menambah channel premium favorit & 0,141 \\
\hline 4 & Upgrade teknologi & 0,155 \\
\hline 5 & $\begin{array}{l}\text { Meningkatkan pelayanan dan } \\
\text { penanganan yang cepat }\end{array}$ & 0,119 \\
\hline 6 & $\begin{array}{l}\text { Membuat promosi khusus kepada } \\
\text { pelanggan dan masyarakat }\end{array}$ & 0,102 \\
\hline 7 & $\begin{array}{l}\text { Melakukan kegiatan pemasaran lebih } \\
\text { intensif dan meningkatkan kinerja } \\
\text { tenaga pemasar }\end{array}$ & 0,090 \\
\hline 8 & $\begin{array}{l}\text { Investasi infrastruktur dengan mem- } \\
\text { buat tiang tumpu kabel sendiri }\end{array}$ & 0,118 \\
\hline
\end{tabular}

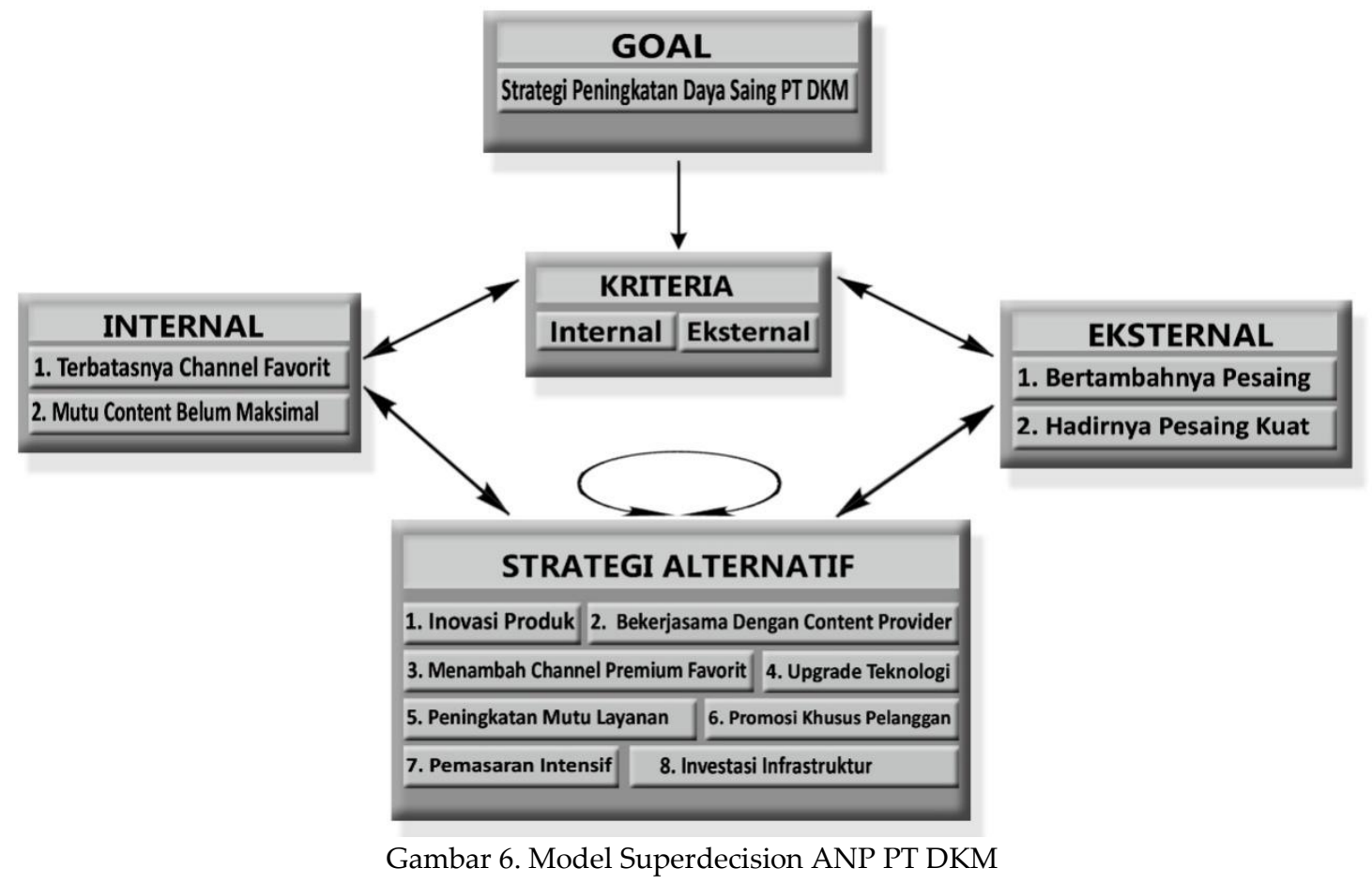


Terdapat delapan strategi alternatif yang diperoleh dari hasil penelitian ini yang bisa diimplementasikan oleh PT DKM sebagai strategi peningkatan daya saing dalam industri TV berlangganan di Kota Payakumbuh. Namun ada tiga strategi yang dianggap paling penting oleh peneliti dan memiliki nilai tertinggi yang harus segera diimplementasikan oleh perusahaan, yaitu strategi meningkatkan kerjasama dengan content provider, strategi upgrade teknologi dan strategi menambah channel premium favorit.

Strategi meningkatkan kerjasama dengan content provider terbaik merupakan strategi alternatif yang paling direkomendasikan atau yang paling diprioritaskan berdasarkan hasil analisis ANP. Strategi ini dapat dengan segera mengatasi masalah internal yang dihadapi oleh perusahaan. Bentuk peningkatan kerjasama yang dimaksud adalah kerja sama dengan content provider yang memiliki beragam channel favorit yang dibutuhkan pelanggan dengan nilai kontrak lebih kompetitif, persyaratan yang ringan, dan masa kontrak lebih lama minimal lima tahun. Perusahaan dapat melakukan kerjasama dengan asosiasi TV kabel Indonesia (ICTA) untuk mewujudkan strategi ini. ICTA baru saja melakukan kerjasama dengan content provider yang memiliki content channel yang lengkap dengan nilai kontrak kompetitif dan persyaratan yang tidak memberatkan perusahaan. Implementasi strategi ini sebaiknya dilakukan sesegara mungkin, mengingat kompetisi di industri TV berbayar bayar semakin meningkat.

Strategi alternatif prioritas kedua bisa diaplikasikan oleh perusahaan adalah upgrade teknologi dengan mengubah jaringan analog yang ada sekarang menjadi jaringan digital. Strategi ini sangat berkaitan dengan dengan strategi pertama. Jaringan digital ini memberikan keuntungan tersendiri bagi perusahaan, dimana biaya maintenance jaringan kabel akan jauh lebih murah, karena masalah yang akan terjadi pada jaringan tersebut jauh lebih sedikit. Hal ini akan berefek kepada penghematan tenaga teknisi. Perubahan jaringan ini membutuhkan biaya yang tidak sedikit. Untuk itu, perusahaan dapat melakukan upgrade jaringan dengan cara bertahap, agar biaya yang ditimbulkan tidak terlalu membebani perusahaan. Strategi alternatif kedua ini harus segera diaplikasikan oleh perusahaan agar mampu menjawab permasalahan internal dan eksternal yang sedang dihadapi perusahaan.
Strategi alternatif dengan bobot tertinggi ketiga adalah menambah channel premium favorit. Penambahan channel premium favorit dapat dengan segera mengatasi masalah internal yang sedang dihadapi perusahaan. Perusahaan dapat menambah channel premium favorit dengan terlebih dahulu melakukan permohonan perubahan dan penambahan channel kepada Kementerian Komunikasi dan Informatika Republik Indonesia. Penambahan channel dapat dilakukan dengan menambahkan content-content premium yang sudah dikontrak atau melakukan melakukan kontrak channel premium yang baru.

\section{KESIMPULAN}

Berdasarkan hasil penelitian strategi peningkatan daya saing PT DKM, maka diperoleh kesimpulan berikut:

1. Kondisi persaingan industri TV berbayar di Kota Payakumbuh berada pada kategori yang sedang.

2. Faktor internal yang memberikan pengaruh terhadap strategi peningkatan daya saing PT. DKM adalah jumlah pelanggan yang cukup besar, telah menjadi market leader di Kota Payakumbuh, harga berlangganan sangat kompetitif dibanding pesaing, memiliki channel bermuatan lokal, teknisi yang handal, kurangnya kinerja tenaga pemasar perusahaan, kurangnya promosi dari perusahaan, kurangnya jumlah channel favorit, mutucontent siaran dan gambar belum maksimal dan masih menggunakan tiang PLN sebagai tiang tumpu kabel. Faktor eksternal yang mempengaruhi strategi peningkatan daya saing PT DKM adalah meningkatnya kebutuhan masyarakat akan hiburan, semakin berkembangnya teknologi TV kabel, pertumbuhan ekonomi masyarakat Payakumbuh yang positif, content premium favorit sebagian besar berasal dari pesaing, banyaknya penyedia content TV kabel, dukungan positif dari pemerintah Kota Payakumbuh, pesaing bertambah, akses dan biaya teknologi internet yang semakin murah dan mudah dijangkau masyarakat, semakin banyaknya promosi yang menarik dari pesaing dan hadirnya pesaing yang kuat.

3. Diperoleh delapan strategi alternatif yang dapat diimplemntasikan perusahaan berdasarkan analisis ANP. Ada tiga strategi 
alternatif yang diprioritaskan yaitu meningkatkan kerja sama dengan content provider terbaik, upgrade teknologi, dan menambah channel premium favorit

\section{DAFTAR PUSTAKA}

Ascarya. 2015. Determining the Cause of Financial Crisis in Islamic Economic Perspective: ANP Approach. Tazkia Islamic Finance and Business Review. 9(2): 109-127.

Azis, I.J. 2003. Analytic network process with feedback influence: a new approach to impact study [tesis]. Urbana (US): University of Illionis at Urbana-Champaign.

[BPS] Badan Pusat Statistik Kota Payakumbuh. 2017. Kota Payakumbuh Dalam Angka. Diakses pada 11 nop 2017: Tersedia pada: https://payakumbuhkota.bps.go.id/backend /pdf_publikasi/Kota-Payakumbuh-DalamAngka-2017.pdf

David, F.R. 2013. Strategy Management, Concept, and Cases 14th. England (UK): Pearson Education Limited.

[DKM] PT Denai Kabel Mandiri. 2016. Data Internal Perusahaan. Payakumbuh (ID). DKM.

Grigore AM. 2014. Book Publishing Business in Rumania-An Analysis from The Perspective of Porter's Five Force Model. Review of International Comparative Management. 15(1): 31-47.

[ICTA] Indonesia Cable TV Association. 2016. Laporan Data Operator TV kabel Anggota ICTA per September 2016. Jakarta (ID): ICTA

[ICTA] Indonesia Cable TV Association. 2015. Laporan Tahun 2015 Indonesia Cable TV Association. Jakarta (ID): ICTA.
[Kemkominfo] Kementerian Komunikasi dan Informatika Republik Indonesia. 2016. Data Internal Subdit Layanan Televisi Direktorat Penyiaran Direktorat Jenderal Penyelenggaraan Pos dan Informatika. Jakarta (ID): Kemkominfo.

[Kemkominfo] Kementerian Komunikasi dan Informatika Republik Indonesia. 2015. Buku Saku Hasil Survey Indikator TIK 2015 Rumah Tangga dan Individu. Jakarta (ID). Kemkominfo. [diunduh 2016 Sep 7]. Tersedia pada: balitbangsdm@kominfo.go.id.

Porter, M.E. 2004. Competitive Strategy: Techniques for Analizing Industry. New York (US): Free Press.

Saaty, T.L., L.G. Vargas. 2013. Decision Making with the Analytic Network Process: Economic, Political, Social and Technological Applications with Benefits, Opportunties, Costs and Risks 2nd ed. New York (US): Springer.

Saaty, T.L. 1999. The Analytical Network Process. Archive of SID [Internet]. [Diunduh 2016 Sep 8]. Tersedia pada: www.sid.ir/en/ vewssid/j_pdf/115720080101.pdf

Shojaei, M., S. Abbaszade, S.S. Aghaei. 2013. Using Analytical Network Process (ANP) Method to Proritize Strategies Resulted from SWOT Matrix. Interdisciplinary Journal of Contemporary Research in Business. 4(9): 603-618.

Sunardi, S. 2012. Strategi Indonesia Dalam Menghadapi Liberalisasi Jasa Telekomunikasi Dalam Kerangka ASEAN Framework Agreement on Services [tesis]. Jakarta (ID): Universitas Indonesia.

Yuksel, I., M. Dagdeviren. 2007. Using The Analytic Network Process (ANP) in A SWOT Analysis: A Case Study for A Textile Firm. Information Sciences. 177: 3364-3382. 